\title{
Ideomaterial Polysystems
}

\author{
Mikhail V. Sukharev* and Galina B. Kozyreva \\ Institute of Economics, Karelian Research Centre of the Russian \\ Academy of Sciences, Petrozavodsk, Russian Federation; \\ suharev@narod.ru,kozyrevakrc@gmail.com
}

\begin{abstract}
Objective: Institutional economics drew the attention of scientists to the fact that ideal constructions (laws, traditions, values, etc.) play an equally important role in the life of society than material systems (people, cities, cars, etc.). The purpose of the article is to search for principles of interaction between the ideal and material foundations of human society. Materials and Methods: Extensive interdisciplinary juxtaposition of the fundamental system theories of material and ideal systems (Jan Smuts's holistic systems, body-mind problem in the lighting of Karl Popper). Finding: It seems to us expedient to introduce the concept of ideomaterial systems, some of the elements of which are material and some of them are ideal. In addition, we prove that human society (including the economy) is a polysystem, that is, a superposition of many fuzzy dynamic systems (economic, religious, scientific, cultural) interacting with each other; each human is simultaneously a member of many subsystems of society. The main resource of social systems is the time that every person gives to participate in them, be it a family, science or football. Applications: The proposed approach of ideomaterial polysystems opens a wide field of research for all social sciences, especially for economics and political science.
\end{abstract}

Keywords: Ideomaterial System, Mind-body Problem, Polysystem, Social Institutes, System Theory

\section{Introduction}

The relationship between the material and the ideal in man and society is still a battlefield between various areas in philosophy and sociology $\frac{1-3}{\text {. }}$. There is also a non-clearcut, but quite noticeable separation between analytical (English-speaking) and continental philosophy, 5 . If the "continental" philosophy still preserves the problematic of the relationship between the material and ideal world (Socrates-Plato-Aristotle-Hegel line), then for "analytic" it is, quite simply, a pseudo-problem. This is even manifested in the translation of the word "idea" (from the Greek "eidos" into English "forms", in which most of the original meaning is lost.

The philosophy of post-Soviet countries retained the problematic of ideal and material in its purest form, borrowing it through Marx, who declared himself was a Hegel student; Soviet textbooks even called these relations "the main question of philosophy". Although communist philosophy in Russia suffered a great defeat, the authors of the article believe, however, that the problem of relations between the material and the ideal obtain a new urgency in connection with the digitalization of society and the development of institutional research. Despite the success of institutional economics, great uncertainty persists about the classification and nature of social institutions ${ }^{6}$. Although institutions are certain rules and regulations, it seems intuitively that simple rules (for example, lapta game) are not institutions; however, is not the institute a game of chess that has theory, textbooks, federations, grandmasters, and so on? So where to draw the line? Moreover, the question of whether social institutions are material or ideal is not considered. For example, many institutionalists consider organizations to be institutions. But organizations are material, aren't they? On the other hand, an organization considered in historical terms no longer seems so definitely a tangible thing. People, tools, buildings, and so on replace each other, everything material is repeatedly replaced, but the organization remains the same.

*Author for correspondence 
So what is an "organization"? Is it its material content or a set of information blocks describing its structure, goals and objectives, job descriptions, technologies used, and so on? But man himself is in this sense is like an organization; the matter in his body is constantly being replaced, but the structure determined by genetic information changes (in the process of growing up and aging) much more slowly. Large social systems, such as nations, states, religions, sciences, engineering disciplines, also have a material, seemingly rigid, but in reality, current basis and the systems of ideas that determine their structure. Although ideas are not material, maintaining them requires constant work, training people, updating texts, and so on. This work has a price. Therefore, the maintenance of any organization requires both material resources and human activities to maintain the ideal part.

In addition to the material and ideal relations, the problem of the interaction of many social subsystems, often without clear boundaries, is interesting. In each state there are subsystems of administration, education, military, economic, scientific, and so on. Their relationship is also of considerable interest to sociology and economics.

\section{Computer Metaphor}

The 20th century completely changed ideas on human thought. Three hundred years before Descartes assumed that thought (soul, complex of all thoughts) is a special non-material substance which connects with the matter of the body, forming an animate being. For that time, such way of thinking was natural, for example, the nature of heat was sought in a special substance - the caloric, which flows from a hot body to a cold one. In the XVII XIX centuries, studies of the nervous system and invention of more and more complex mechanical devices have already caused many guesses that the brain is a complex machine and this is not a matter of some substance, but in the processes in this machine. But only the 20th century, appearance of computers, their penetration into almost every home, convinced many people that the brain is a very special, very powerful computer.

Analogy between functions of the brain and the computer, the "computer metaphor", is one of the methodological backgrounds of cognitive science. “... In the early 1960s, cognitive processes were interpreted by analogy with computing processes in the computer", writes one of the leading Russian researchers in cognitive psychology?
The essence of computer metaphor is that the brain is considered as a system for processing signals which are transferred by the processes in the cognizable material system available for investigation and reproduction. There upon, modern neurophysiology has appeared. Computer metaphor works in both directions; it allows biologists, psychologists and physiologists to understand the brain, based on computer analogies, and computer developers to create new architectures, starting from the brain structure. They pay close attention to brain research and try to use opened principles. These principles are, for example, the basis of the latest neural processing units. Computer metaphor is a way of thinking allowing using ideas from the IT field to understand the processes in the brain and vice versa, to use data on the brain to create advanced computer architectures.

Because of idea in the scientific community that a person is a special computer, metaphor inevitably penetrates into sociology, especially with the widespread penetration of computer social networks. The idea of society as a social multiprocessor cognitive network, where people play the role of processing units, forming a unified system of knowledge creation, will inevitably change in the near future the idea of the nature of mind.

\section{Ideomaterial Systems}

These are systems, part of which elements is material, and part is ideal one. An example of such a system is the wellknown personal computer today. Even if its material part is in perfect order, but the operating system and application programs are not loaded, it cannot function. Here it should be emphasized that information (and programs in particular) is non-material, no one single atom of matter gets into the computer memory when downloading programs either from a laser disk or the Internet; transferred is organization of states of matter, patterns of magnetization of the surface of magnetic disks, light rays (reading of laser disks), states of memory cells, and so on. Aristotle wrote: "Thus, speaking generally, the sensation is the power which receives the sensible forms (aistheton eidon) without matter, just like wax that receives the imprint of a signet-ring without its iron or gold and receives the gold or bronze object, but without gold or bronze as such" A program (knowledge, information) is transmitted either from a laser disk or from the Internet in the same way as an imprint of a signet-ring is transmitted, without transferring the matter storing the original image. But it 
should be understood that the state of material objects acting on each other is only a means, and the goal is the transfer of a pattern.

Information accepted by the system (and knowledge, as a special kind of information) changes its state and behavior. The identical initial source systems that have adopted different sets of information will become new and already different systems. If we load different operating systems and different programs in two identical computers (for example, games in one computer, and mathematical analysis package in another game), they will behave in completely different ways. That is, the behavior of an ideomaterial system can change radically while maintaining the material part and replacing the ideal part.

If we look at a person as an ideomaterial system relying on a computer metaphor, then we will see a certain similarity. For example, twins, brought up in different societies, can speak different languages and practice completely different beliefs. In economic terms, even identical twins (genetically identical), loaded with different human capital assets (for example, one of them is a musician, and the other is a physicist), are completely different units of labor force. As material systems, they are very similar, but their ideal subsystems are different. Even society as a whole can be "reloaded" by a new ideology that Russia experienced in 1917 and 1991. Social ideology is more like an operating system, that is, a program which controls the execution of other programs.

Ideology determines which more specific laws (formal institutions) will be abolished and which will be accepted, which knowledge will be taught and which will be rejected, ensuring the constant updating of the ideomaterial system of society as a whole. This is similar to the view what consider culture (the prototypical cultural systems are those of beliefs and ideas) to be one of the basic subsystems of society, which implies "generalized complexes of constitutive symbolisms that give the action system its primary "sense of direction"? Parsons also considered a person as an entity defined by its cultural content: "Personality, then, is the aspect of the living individual, as "actor," which must be understood in terms of the cultural and social content of the learned patternings that make up his behavioral system" (ibid.).

It is necessary to mention the important property of many systems, namely, holism. The term "holism" introduced into the modern scientific circulation South Africa in 1926, which paid close attention to the phenomenon of system integrity and its internal connection with the evolution processes. The following is a great quote from the book of Smuts: "Both matter and life consists of unit structures whose ordered grouping produces natural wholes which we call bodies or organisms. This character of "wholeness" meets us everywhere and points to something fundamental in the universe. Holism (from ö $\lambda$ o $\varsigma=$ whole) is the term here coined for this fundamental factor operative towards the creation of holes in the universe. Its character is both general and specific or concrete, and it satisfies our double requirement for a natural evolutionary starting-point. Wholes are not mere artificial constructions of thought; they actually exist; they point to something real in the universe, and Holism is a real operative factor, a vera causa. There is behind Evolution no mere vague creative impulse or Elan vital, but something quite definite and specific in its operation, and thus productive of the real concrete character of cosmic Evolution. The idea of wholes and wholeness should therefore not be confined to the biological domain; it covers inorganic substances and mental structures as well as the highest manifestations of the human spirit" 10 .

\section{Polysystemic of Society}

Let us consider some subsystems of society as ideomaterial systems, consider their construction and their components, the methods of their self-reproduction and their relations with other subsystems. Vivid examples of ideomaterial systems are religions. Any religion as a system includes believers, priests (scholars), and religion itself as a corpus of scriptures, a description of the internal structure of the church, rules of conduct of believers and priests. Religion cannot exist without a material carrier, without believers.

Most developed religions (namely, as ideomaterial systems, that is, systems of material and ideal elements) include temples (sacred buildings used for ceremonies), sacred books, special robes for clergymen, religious objects. Their ideal part (belief system) is, in essence, the supporting structure connecting all others. Without religion as a system of ideas, all material parts are deprived of meaning, temples, ecclesiastical robes and oil lamps turn out to buildings, bathrobes and lamps poorly adapted for everyday life. But religions filled with their ideological content turn out to be the engines of history.

Let us take into consideration a much more earthbound subsystem of society - railways. They have quite a 
material basis, clearly organized into the holistic system. It includes the paths themselves (with embankments, sleepers, rails, arrows), traffic lights, stations, bridges, depot, locomotives, cars, and so on. It includes workers of many different types and ranks. But besides this, there is a huge amount of regulatory and technical documentation, without which disasters will immediately begin and in a short time the entire system will cease to operate. Of course, this system of rules and instructions exists not only on paper, but also in the heads of railway workers, but you need to understand that initially this is a single system of ideas which is only stored in different ways and is transmitted both through printing houses and digital communications, and teachers in colleges and institutes.

It is possible to take any science as an example of the ideomaterial system. Science also consists of a system of ideas (knowledge and information). But it also consists of scientists who know this science, reproduce it by teaching new scientists at universities, setting it in motion thanks to its activities. And in many cases, science includes special scientific instruments, without which scientists would lose contact with their objects of study: telescopes, accelerators, sequencers, and so on. The buildings in which all this should be placed are also called "institutes".

Each science has its own special language in which the same words can be used, taken from their common language, but having a different meaning, understood by members of the scientific community. For example, in biology, the "nucleus" is most likely the nucleus of a cell, in physics the nucleus of an atom, and in astronomy the central part of a celestial body (planets, stars, comets). The entire huge material building of a specific science (for example, physics or biology, today there are hundreds of thousands of scientists, thousands of institutes and universities in the world, very complex and expensive installations) would have lost their meaning without science itself as a system of knowledge, a system of ideal elements.

What are these ideal systems fulfilling the role of a nonmaterial skeleton for large subsystems of modern society? All ideal systems are similar to what the "paradigm": "For present purposes I suggest "disciplinary matrix": "disciplinary" because it refers to the common possession of the practitioners of a particular discipline; "matrix" because it is composed of ordered elements of various sorts, each requiring further specification. All or most of the objects of group commitment that my original text makes paradigms, parts of paradigms, or paradigmatic are constituents of the disciplinary matrix, and as such they form a whole and function together" $" 11$.

Here, "practitioners" can be replaced by "priests" or "railroad workers", they still share some complex multi-level matrix of ideological positions, and also accept their membership in this community. Body of knowledge, culture (civilization?), ideal stratum of society are the totality of all non-material components, which acts through the people constituting the society, while remaining non-material one.

\section{Psychophysical Problem}

In the concept of ideomaterial systems we are faced with an old, but still not completely resolved psychophysical problem (known also as mind-body problem) of philosophy. This is the problem of the relationship of soul and body, consciousness and organism, material and ideal. Karl Popper formulated a psychophysical problem like this: "We live in a world of physical bodies, and we ourselves have physical bodies. When I speak to you, however, I am addressing myself not to your bodies but to your minds. So in addition to the first world, the world of physical bodies and their physical and physiological states, which I will call "world 1" there seems to exist a second world, the world of mental states, which I will call "world 2". Here raises the question of interaction between these two worlds, the world of physical states or processes and the world of mental states or processes. This question is a body-mind problem" $\stackrel{12}{ }$.

Due to human egocentrism, a body-mind problem was considered mainly in the context of the relationship between the consciousness of a person and his/her body; but it is also possible to pose this problem for the relations of culture and the material system of society.

Popper posed the problem of objective knowledge in a new way by distinguishing general knowledge (culture belonging) from individual knowledge. He introduced the concept of world 3, the world of general cultural knowledge, distinguishing it from the world 1 (physical one) and world 2, to which the consciousness of the individual belongs. Individual knowledge disappears together with the individual, and cultural knowledge does not depend on individuals, and in this sense it is objective (not subjective).

Among these philosophical arguments, it can be recalled that human capital asset, considered in economics, arises as a result of transfer of a certain part of knowledge from the general culture of society (world 3) to the consciousness of an individual (world 2). 


\section{Karl Popper's World 3}

Popper defined the "world 3" in this way: "By "world 3" I mean, roughly, the world of the products of our human minds. These products are sometimes physical things such as the sculptures, paintings, drawings, and buildings of Michelangelo. These are physical things, but they are a very peculiar kind of physical things: in my terminology they belong to both the worlds 1 and 3. Some other products of our minds are not precisely physical things. Take a play by Shakespeare ... no single performance of Hamlet can be said to be identical with Shakespeare's play Hamlet itself ... the play may be said to be represented or reproduced by these performances ... We cannot understand world 2, that is, the world inhabited by our own mental states, without understanding that its main function is to produce world 3 objects, and to be acted upon by world 3 objects" $\underline{12}$.

In other words, being human means carrying a part of culture of society (world 3 -> world 2) and being exposed to social attitudes, values, institutions, knowledge, groupings and trends. This does not mean that a person is not free. Culture is quite large, diverse and multidimensional. An individual has a huge field for movement within the culture and is able to even create new cultural entities within his/her second world, then bringing them into the world 3 (if it accepts these ideas) and making them immortal. But being objectified and brought into the field of social consciousness (noosphere ${ }^{13}$ ), ideal objects acquire their own lives being independent of a creator. Invented (opened) ideal elements and laws of their interactions make it possible to create a multitude of new combinations (systems), unforeseen by a creator. So, for example, the creators of a number series did not foresee many of its properties, for example, the problems of prime numbers or countable sets which arise as a result of a combination of the original simple concepts of number, addition, and so on. Faraday did not foresee the appearance of smartphones ... Having become a part of the third world, ideas are no longer belonging to a separate brain. They are almost impossible to destroy, and all new people build new combinations of them.

\section{Polysystemic World 3}

Popper's world 3 (or socialized ideas) also turns out to be composed of a set of ideal systems superimposed on each other (or subsystems of culture as a whole). The most developed of them (for example, science) are quite autonomous and have their own language.

The elements in these systems are concepts (atom, cell, charge, byte, gene, class, capital, and so on), and laws of these system link the concepts in the system. The laws of interaction of physics say that bodies with mass and opposite charges attract, the laws of mathematics say that numbers are added and multiplied, the laws of economics speak about the connection of labor and capital, prices and the amount of money in circulation, and so on. Knowledge of these laws allows scientists who have mastered the language of science building in their mind arbitrary systems of these elements related by interactions taken from laws.

But at the same time, each science is quite distinctly separated from the others (although there are extensive areas of mutual penetration, for example, biophysics, astrophysics, economic psychology, etc.). This autonomy is associated with the organization of scientific communities that, in order to preserve integrity, are forced to make common decisions. Of course, the organization of sciences is much less rigid and more flexible than the organization of the army or state bodies, but effective enough to keep them within certain limits. Wrote that the paradigm is what the members of a scientific community share, and, conversely, a scientific community consists of humans who share a paradigm ${ }^{10}$. None of the scientists can work alone without using the ideas and data of other scientists; otherwise they will constantly reinvent the wheel. But the community is always starting to create an organization to avoid chaos in communication and ideas. The elements of this organization are scientific schools, academies, journals, universities, scientific foundations, and so on.

Being relatively autonomous, sciences constantly and productively interact. All sciences in one way or use mathematics, and often the needs of other sciences cause the emergence of new trends within mathematics. Many sciences use physical theory or physical tools. There is a strong connection between sociology and anthropology, although they both do not recognize for decades the undesirable data from neighboring science. In addition to the sciences, there are other equally stringent and autonomous ideal systems of world 3. This is the world of laws, formal institutions of developed societies. The laws of society are objective ones; they exist outside and independently of each individual consciousness (but not all at once). But the laws of the state, like the laws of physics, 
do not exist by themselves; they exist in the separate minds of thousands of lawyers, judges and other legal workers, and in their general consciousness, which is supported by words and texts. Laws are written in a variety of documents and are stored in thousands of libraries. There are special organizations of people who are called upon to interpret laws, make decisions on them and force them to be executed.

The institutional matrices $\frac{14}{}$, which are the basic holistic systems of social organization, are located deeper than formal laws. There are already mentioned religions with their textbooks and rules of internal behavior. There are political parties with their own charters and hierarchies. In addition, there are a huge number of less strict communities, for example, the community of chess players or philatelists. However, it can be noted that chess is much closer to the sciences in its structure, rules and theory of chess and the hierarchy of experts, confirmed by the system of championships.

If to take into consideration any company, university, or other corporation, we will see that people are replaced in them, like cells in the body, but the organizations themselves sometimes exist for hundreds of years. They have an internal structure (charter and other documents), a set of knowledge and skills necessary to perform their functions. An individual can be a member (element) of many communities at the same time. $\mathrm{He} / \mathrm{she}$ can be a mathematician, work in a particular institute, be a chess player, a believer in any religious denomination, and a member of a political party. The number of combinations is very large. But each such community has a certain system of ideas, a paradigm which they share and which keeps them in their field, despite their non-material nature.

Some of these communities are inscribed inside state systems (for example, political parties and law systems usually operate within individual states), some are not related to the division of the world into countries (for example, biology, religions, or same chess, although a strong correlation of religions with civilizations can be seen). Individual ideal systems may appear incompatible, even semantically. The system of concepts of physics (mass, energy, speed, charge, voltage... and interactions between objects) is incompatible with the concepts of sociology or economics. But there is a system of transitions (corridors): physics - engineering, physics - chemistry, physics biology, chemistry - biology, biology - anthropology, anthropology - sociology, sociology - economics). The integrity of science and communication with the real world is realized through these transitions.
Legal systems are associated with specific states, but institutional matrices are wider than state borders and are connected, like religions, with civilizations. However, they do not have clear boundaries, being subject to borrowings and modifications in the zone of interaction with other civilizations. At the same time, all these partial ideal and material systems are based on large fundamental platforms, such as a common language, legislation, and economics.

\section{Polysystems of Even-Zohar}

Even-Zohar defined polysystems as socio-semiotic phenomena, sign-governed human patterns of communication such as culture, language, literature $e^{15}$. As a linguist, he was primarily interested in the problems of the meaning of texts in different cultures and the preservation of the meaning of the text when it is translated into another language. With a deep study of these problems, he was faced with the fact that every text exists among other texts (polysystem) in the original culture, and once transferred to another culture as a result of translation; it turns out to be in an ecosystem of completely different texts.

But this principle should be transferred to all social phenomena and is particularly relevant in institutional economics. The process of adaptation of borrowed institutions turns out to be very similar to the translation of text from another language, often the language of a very different culture.

"Considering them as systems, i.e., as networks of relations which can be put forward as hypotheses foraspecificsetofsupposed observables("manifestations"/ "phenomena"), suggest how the various socio-semiotic aggregates work" ${ }^{15}$. Polysystems are dynamic and heterogeneous, in contrast to the synchronistic approach. "This means that any isolating part of a culture may have to be studied in correlation with other sections in order to better understand its nature and function. For example, formal culture requires studying informal culture; a standard language can be better understood, placed in the context of non-standard dialects; prestigious types of texts may be associated with less prestigious, etc." (ibid).

So, social polysystems are dynamic systems of superimposed, partially interacting, partially autonomous ideal and material subsystems, together creating civilizations and states. 


\section{Competition of polysystems}

An ideal system can exist only in the minds of people (or, probably, AI). Currently, some of the polysystems are implemented in computers which store and process information and (more significantly) support a variety of models of various processes. In order to reproduce themselves, ideal systems (be it chess or religions) must master people's minds. Although human consciousness (or a digital processor) can simultaneously support several ideal systems, but "processor time" and memory capacity are limited, therefore there is always competition among ideal systems for processor resources. Competition between the sciences goes both through the potential of their contribution to the economy, and through the potential of their contribution to the safety of society as a whole (outlook in the world with a view to seeing prospects and dangers, knowledge of man and society, including health and ecology) and through the potential of their contribution to security of public systems.

In any case, people and society have to carefully weigh the time spent on studying (reproduction in the next generations), using and developing ideal systems.

With economic and ideological incentives, some ideal systems quickly spread and developed, involving more and more people. For example, physics, thanks to its contribution to the economy and military technology over the course of the 20th century, increased its share in the government expenditures and the number of people involved in its support by hundreds of times. Digital technology and biology are currently experiencing explosive growth.

\section{Ideal Systems as Sign Systems}

Ideal systems are sign systems. The economy is primarily interested in social institutions, but institutions (including informal ones) are formulated and transmitted through the language, and therefore also belong to sign systems. A great contribution to the development of the theory of sign systems. He wrote: "The main issues for describing any semiotic system are, firstly, its relation to outside the system, to the world beyond its borders, and, secondly, the relation of statics to dynamics" 16 .

These words are quite applicable to the complex of social institutions which regulate the life of society. Economists are just interested in how the system of rules of behavior in society affects the success of the life of this society in its environment, including nature and other neighboring communities. Another citation: "Semiotic space appears to us as a multi-layered intersection of various texts, which together form a certain stratum with complex internal correlations, different degrees of translatability, and untranslatability spaces. Under this stratum there is a layer of "reality" - that reality, which is organized in various languages and is in hierarchical correlation with them. Both of these layers together form the semiotics of culture. Beyond the semiotics of culture lies the reality that is beyond the limits of language" 16 .

In this text one can see a non-random similarity with Even-Zohar polysystems. The social phenomena are conceptually polysystem ones, and so is the economy. Although it is improper to cite extensive quotations, but it is difficult to say better: "A person immersed in the cultural space inevitably creates an organized spatial sphere around himself/herself. This sphere, on the one hand, includes ideological ideas, semiotic models, and on the other, recreating human activity, since the world artificially created by people - agro-cultural, architectural and technical ones - correlates with their semiotic models.

The relationship here is mutual: on the one hand, the architectural structures copy the spatial image of the universe, and on the other, this image of the universe is built by analogy with the world of cultural structures created by a person. ... A spatial pattern of the world is multilayered: it includes mythological universum, scientific modeling, and every day "common sense". At the same time, for normal person these (and a number of others) strata form a heterogeneous mixture, which functions as one thing." ${ }^{\prime \prime}$. Indeed, the entire culture of society is entirely a condition for its successful economic activity. Science is the basis of technology, customs and laws are the basis of the sustainability of society, architecture features inherent in this society are associated with its environment, and even national costume is a condition of life in a characteristic climate.

The following statement is applicable to the consideration of the ideal layer of ideomaterial systems as a relatively autonomous and active Popper's world 3: "Nowadays it would be possible to give a more generalized definition (of culture): the totality of all non-hereditary information, methods of its organization and storage. ... But culture is not a "store room" of information. This is an extremely complex organized mechanism which stores information, constantly exploring the most advantageous and compact methods for this, receives new information, 
encrypts and decrypts messages, translates them from one system of signs to another. Culture is a flexible and complexly organized mechanism of knowledge." (ibid).

\section{Result and Discussion}

The economic and sociological literature examines various aspects of the evolution and structure of institutional systems. However, the clear boundaries of which of the social rules of behavior and ways of solving problems is, and which are not institutions, remain uncertain. It seems that in addition to formal institutions and generally accepted rules of conduct, which are unambiguously considered social institutions, there are many local (adopted only in this organization) or temporary, as well as professional rules and regulations that constitute the ideal framework for organizing of work, study, play, and understanding of one's place in the world. In society there are many strongly or weakly interacting subsystems, each of which plays a certain role. A person can be simultaneously a member of several subsystems (economic organization, religious denomination, sports club, political party). We propose the approach to examining such subsystems as the ideomaterial, that is, including people, artifacts and a system of ideas (information), determinative the structure and functions, creates a new wide field of social and economic research.

We propose the approach to examining such systems and subsystems as the ideomaterial systems, that is, objects that includes people, artifacts and the system of ideas (information), which determine the structure and functions. The approach creates a new wide field of social and economic research. Consideration of national states as ideomaterial polysystems, each of which, in order to continue its existence, requires both material resources and the human activity for maintenance of the ideal components, makes it possible to study their dynamics and look for equilibrium models of their existence.

\section{Acknowledgment}

This research was supported by the Russian Foundation for Basic Research, project N 17-06-00691A.

\section{Conclusions}

Humanity as a whole is a super-complex self-replicating and evolving system. Modern states are subsystems of humanity as a whole, which in relation to them is a polysystem. There are other subsystems within states: economy, army, government, science, etc. All of these subsystems belong to the ideomaterial systems. They have a complex material part (for example, the economy as a whole includes peoples, infrastructure, means of production, transport, and more) and ideal part (the ideal part of the economy is the knowledge of entrepreneurs and managers, technological knowledge, millions of contracts, etc.). There is a competition between these subsystems for resources (human, material and ideal) within society. This competition goes partly through the market and partly through power. The study of the dynamics of human societies through the prism of ideomaterial systems can be of considerable interest for economic science and sociology.

\section{References}

1. Welton WA. Plato's forms: varieties of interpretation. Lexington; 2002. p. 1-321.

2. Alican NF, Thesleff H. Rethinking plato's forms. Arctos: Acta Philologica Fennica. 2013; 47:11-47.

3. Ludwig K. The mind-body problem: An overview. The Blackwell Guide to Philosophy of Mind. Blackwell; 2002. p. 1-46.

4. Bell JF, Cutrofello A, Paul M. Beyond the analyticcontinental divide: pluralist philosophy in the twentyfirst century. Routledge; 2015. p. 1-334. https://doi.org/ 10.4324/9781315766621

5. Levy N. Analytic and continental philosophy: explaining the differences. Metaphilosophy. 2003; 34(3):284-304. https://doi.org/10.1111/1467-9973.00274

6. Stanford encyclopedia of philosophy archive [Internet]. [cited 2011 Feb 08]. Available from: https://plato.stanford. edu/archives/win2014/entries/social-institutions/.

7. Velichkovskii BM. Cognitive science: fundamentals of cognitive psychology: in 2 volumes. Muslim Youth Soccer League: Akademiia Publishing House; 2006. p. $1-448$.

8. Aristotelous, peri psyches: traité de lâme [Internet]. Available from: https://archive.org/details/aristotelousper00rodigoog/ page/n7.

9. Sills DL. International encyclopedia of the social sciences. (Ed). Macmillan. 1968; 15:458-73.

10. Smuts Hon JC. Holism and evolution. Macmillan and Company Limited; 1927. p. 1-398.

11. Kuhn TS. The structure of scientific revolutions. 3rd Edition. University of Chicago Press; 1996. p. 1-212. https:// doi.org/10.7208/chicago/9780226458106.001.0001 
12. Popper KR. Knowledge and the body-mind problem: In defence of interaction. Routledge; 1994. p. 1-170.

13. VernadskyVI.Scientific thought as a planetary phenomenon. Moscow, Nongovernmental Ecological Foundation; 1997. p. $1-265$.

14. Kirdina SG. Institutional matrices and development of Russia: an introduction to the X-Y-theory. 3rd Edition.
Expanded and illustrated. SPb.: Nestor-Istoriia; 2014. p. 1-468.

15. Even-Zohar I. Polysystem studies. Poetics Today. 1990; 11(1):1-262.

16. Lotman J. On the semiosphere. Sign Systems Studies; 2005. p. $1-25$. 